\title{
Collaborative Care to Relieve Psychological Distress in Patients with Medically Inoperable Lung Cancer: Design and Rationale for a Clinical Trial
}

\author{
Seon-Young Kim ${ }^{1,2}$, Sung-Wan Kim¹, Il-Seon Shin ${ }^{1}$, In-Jae Oh ${ }^{3,4}$, \\ Cheol-Kyu Park ${ }^{3,4}$, Young-Chul Kim ${ }^{3,4}$, and Jae-Min Kim ${ }^{1}$ \\ 'Department of Psychiatry, Chonnam National University Medical School, Gwangju, Republic of Korea \\ ${ }^{2}$ Mental Health Clinic, Chonnam National University Hwasun Hospital, Hwasun, Republic of Korea \\ ${ }^{3}$ Department of Internal Medicine, Chonnam National University Medical School, Gwangju, Republic of Korea \\ ${ }^{4}$ Lung and Esophageal Cancer Clinic, Chonnam National University Hwasun Hospital, Hwasun, Republic of Korea
}

\begin{abstract}
Psychological distress is common in lung cancer patients with a poor prognosis. The present study aims to investigate the efficacy of collaborative care for patients with newly diagnosed inoperable lung cancer in South Korea. The study is a three-arm parallel-groups nonrandomized clinical trial with an active arm that includes distressed patients who receive collaborative care, one comparison arm that includes distressed patients who receive enhanced usual care, and another comparison arm that includes non-distressed patients. In total, 267 consecutive patients newly diagnosed with medically inoperative lung cancer will be recruited. The primary outcomes are the changes in Hospital Anxiety and Depression Scale-depression and the Distress Thermometer at 12 and 32 weeks after enrollment. Sub-analyses of patients in the active arm of the study will include a comparison of the efficacy of a combination of oral antidepressant (escitalopram) treatment and collaborative care versus that of collaborative care alone.

Psychiatry Investig 2019;16(7):547-553
\end{abstract}

Key Words Collaborative care, Lung cancer, Distress, Depression, Clinical trial.

\section{INTRODUCTION}

\section{Psychological distress in cancer patients}

Every year, more than 200,000 patients are newly diagnosed with cancer in South Korea. ${ }^{1}$ The unmet needs of patients in terms of psychological distress have increased as cancer survival rates have improved, ${ }^{2}$ and these needs are greatest in the several months following diagnosis. ${ }^{3}$ There are several welldocumented risk factors for psychological distress, including younger age, a history of psychiatric illness, poor social support, advanced cancer, functional impairment, and uncontrolled pain. ${ }^{4}$ Additionally, biological factors, such as activation of the hypothalamic-pituitary-adrenal axis or low vitamin D levels,

Received: January 21, 2019 Accepted: March 9, 2019

$\bowtie$ Correspondence: Jae-Min Kim, MD, PhD

Department of Psychiatry, Chonnam National University Medical School, 160 Baekseo-ro, Dong-gu, Gwangju 61469, Republic of Korea

Tel: +82-62-220-6143, Fax: +82-62-225-2351

E-mail:jmkim@chonnam.ac.kr

(c) This is an Open Access article distributed under the terms of the Creative Commons Attribution Non-Commercial License (https://creativecommons.org/licenses/by$\mathrm{nc} / 4.0$ ) which permits unrestricted non-commercial use, distribution, and reproduction in any medium, provided the original work is properly cited. are associated with psychological distress, ${ }^{5,6}$ and genetic components, such as the serotonin transporter (5-HTT) and brainderived neurotrophic factor (BDNF) genes, are responsible for vulnerability to depression in cancer patients. ${ }^{7}$

\section{Collaborative care and management of distress}

Screening for and management of distress in cancer patients are recommended, ${ }^{4}$ but very few patients have their psychosocial needs met during cancer treatment. ${ }^{8}$ Barriers to the utilization of psycho-oncological services include stigma, preference for self-management, lack of information, need for confidentiality, and a busy schedule., ${ }^{9,10}$

Collaborative care models can increase the accessibility of mental health services, and thus may be helpful in overcoming these barriers to successfully managing depression in cancer patients. ${ }^{11}$ Several previous randomized trials of collaborative care for cancer patients have been conducted. In the USA, two trials found improvements in depression and QoL in patients with various types of cancer. ${ }^{12,13}$ In the UK, the Symptom Management Research Trials (SMaRT) oncology-1 and -2 studies reported similar results for patients with various types of 
cancer. ${ }^{14,15}$ The SMaRT oncology-3 study recruited lung cancer patients found that the collaborative care group exhibited significant improvements in depression, anxiety, and QoL compared to the usual care group. ${ }^{16}$ Likewise, a recent metaanalysis of collaborative care interventions reported favorable effects in cancer patients. ${ }^{17}$

\section{Studies in lung cancer patients}

Advanced lung cancer patients were reported a very poor prognosis; the 5-year survival rate of this population is less than $40 \% .{ }^{18}$ Consequently, this group of patients has the highest prevalence of psychological distress among cancer patients. ${ }^{19}$ More than one-third of lung cancer patients report depression prior to treatment, and this persists in more than $50 \%$ of patients. ${ }^{12}$ The suicide risk of cancer patients is 12 times higher than that of cancer-free patients, particularly within 12 weeks of the initial diagnosis. ${ }^{20}$ Younger age, functional impairment, physical symptom burden, and fatigue are risk factors for distress in lung cancer patients. ${ }^{21,22}$ Considering the high prevalence of distress in lung cancer patients, interventions for managing distress are necessary, but few clinical trials have addressed the issue in this population.

\section{Limitations of the previous studies}

Despite the promising findings of previous studies, they have had several limitations. Most of these studies were conducted in the USA or the UK, ${ }^{12-17}$ and a cumulative meta-analysis of collaborative care found heterogeneity among the results of US studies and non-US studies. ${ }^{23}$ This heterogeneity could be due to differences in the health care system of each country and/or the degree of fidelity to the original collaborative care model. ${ }^{11}$ Thus, trials assessing collaborative care in Asian cancer patients are necessary, but few has been published to date. Meanwhile, of the trials that have been published, few investigated advanced cancer patients, who frequently report severe distress, ${ }^{24}$ and most enrolled patients were in various phases of cancer treatment even though psychological adaptations to this disease differ by timepoint. ${ }^{25}$ Furthermore, no information regarding genetic vulnerability to psychological distress or its relationship with psychological interventions in lung cancer patients is available. Finally, whether the use of collaborative care to manage distress will improve psychological symptoms and/or quality of life to a level similar to non-distressed patients remains unknown.

To overcome the limitations of previous trials, the present authors designed a clinical trial of collaborative care in South Korea. The target population is patients with medically inoperable lung cancer who had a poor prognosis and/or advanced stage of disease.

\section{Trial hypothesis}

To ensure homogeneity with respect to the phase of cancer treatment, the enrollment period was limited to patients within 3 months of their initial lung cancer diagnosis. To understand the efficacy of the intervention, the collaborative care intervention group will be compared to two control arms: a group of patients with distress who did not want the intervention and a group of patients without distress. Thus, this study is a non-randomized clinical trial with a three-arm parallel-group design that investigates the efficacy of collaborative care for patients with newly diagnosed inoperable lung cancer in South Korea. The primary hypothesis is that the collaborative care group will report less psychological distress than the enhanced usual care (EUC) group but greater distress than the non-distressed group at 12 and 32 weeks after enrollment. The secondary hypotheses are that QoL, level of functioning, and other psychological/physical symptoms will show greater improvement in the collaborative care group than in the EUC group, but will remain worse than the levels of the non-distressed group. Third, it is hypothesized that a sub-analysis of the collaborative care group will show that psychological distress will improve more rapidly in the patients that receive a combination of oral antidepressant treatment and collaborative care compared to those who receive collaborative care alone.

\section{METHODS}

\section{Design}

This study is a three-arm parallel-group non-randomized clinical trial that collects primary outcome data at 12 and 32 weeks after enrollment. The CONSORT flow chart of the study is presented in Figure 1.

\section{Recruitment and eligibility criteria}

Participants are consecutively recruited from the Lung and Esophageal Cancer Clinic at Chonnam National University Hwasun Hospital, South Korea. The inclusion and exclusion criteria are summarized in Table 1 . Because this trial will include a sub-analysis of escitalopram treatment, patients who has an acute hemorrhagic risk, a corrected QT interval >500 $\mathrm{ms}$, and/or a severe renal function impairment are excluded to protect the participants from potential risks. ${ }^{26,27}$

\section{Baseline demographic and clinical characteristics}

The following sociodemographic and clinical data are obtained via interview or clinical record at baseline: age, sex, years of formal education, history of alcohol and/or smoking, history of depression and/or anxiety, and information about the cancer. Genetic and serological information regarding the 


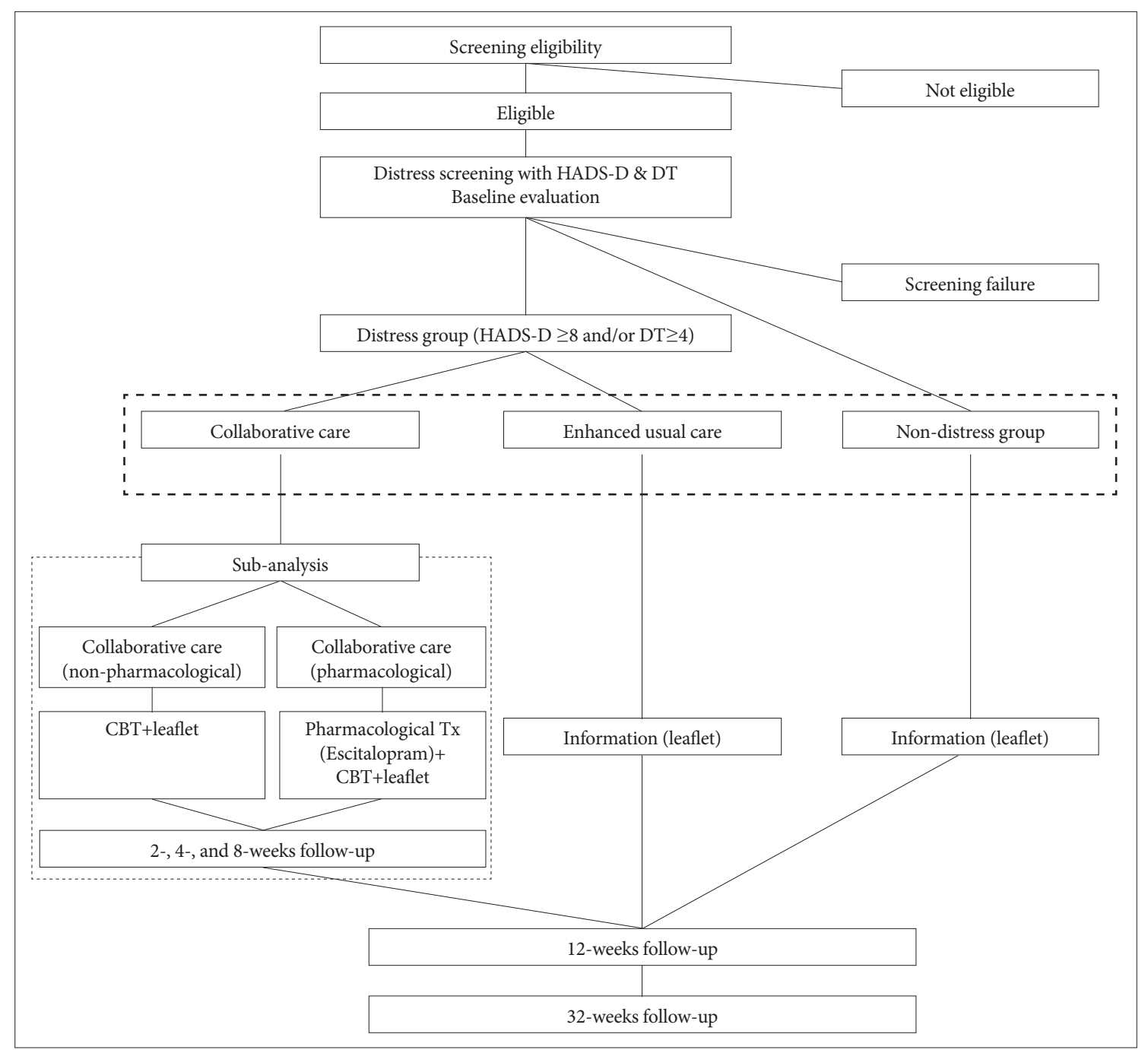

Figure 1. Flow chart of the trial. The box with thick broken line is main trial arms, and with thin broken line is sub-analysis arms. CBT: cognitive behavioral therapy, DT: Distress Thermometer, HADS-D: Hospital Anxiety and Depression Scale-depression, Tx: treatment.

5-HTT and BDNF genes and vitamin D, respectively, are also collected. Personality and religiosity are assessed using the Korean version of the 10-item Big Five Inventory (BFI-10) $)^{28,29}$ and the Duke religion questionnaire, ${ }^{30,31}$ respectively.

\section{Participants allocation and treatment}

\section{Distress screening and arrangement}

Patients who met the eligibility criteria and agreed to participate in the study are screened for distress using the Hospital Anxiety and Depression Scale-depression (HADS-D) ${ }^{32,33}$ and Distress Thermometer (DT). ${ }^{34}$ Based on previous studies, ${ }^{33,35}$ patients who scored $\geq 8$ on the HADS-D and/or $\geq 4$ on the DT at the screening are categorized as distressed, and all others are categorized as non-distressed. Following patient allocation into the distressed and non-distressed groups, patients in the distressed group are categorized into the collab- orative care group or the EUC group based on individual preference.

\section{Collaborative care group (Active arm)}

The collaborative care model is based on the published literature, i.e., the Depression Care for People with Cancer (DPCP) model. ${ }^{36}$ The cancer team (pulmonologists and pulmonology coordinators) and psycho-oncology team (psychiatrist and care manager) care for a lung cancer patient and communicate with each other. The care manager is a trained nurse who delivers the intervention to patients under the regular weekly supervision of a psychiatrist. The intervention consists of eight sessions of low-dose cognitive behavioral therapy (CBT) based on the Oxford Guide to CBT for People with $\mathrm{Cancer}^{37}$ and Minding the Body: Workbook texts, which have been translated into Korean. ${ }^{38}$ These sessions are delivered face to face or via telephone. The first four sessions are delivered to patients 
every week after group allocation, and the remaining four sessions are delivered to patients every 2 weeks thereafter. Other than Session 1, the order of the sessions can be changed flexibly based on the patient's physical and/or psychological condition. The patients also receive an educational leaflet three times throughout the 12-week treatment period (Table 2).

It will be also recommended that all patients in the collaborative care group concurrently undergo antidepressant treat-

Table 1. Selection criteria of the study

Inclusion criteria
Older than 25 years of age
Newly diagnosed with primary lung cancer within 3 months
Medically inoperable lung cancer
Can speak Korean
Can understand the purpose of study
Exclusion criteria
Dementia or other major cognitive impairment
Acute suicidal risk or psychotic symptoms
History of psychotic disorders
Acute massive hemorrhagic event within 1 week
Platelet count $<130,000$ per $\mu \mathrm{L}$
Corrected QT interval $>500 \mathrm{~ms}$
Severe renal function impairment
(creatinine clearance $<30 \mathrm{~mL} / \mathrm{min}$ )
Taking antidepressant in the enrollment period
Untreated or remnant another primary cancer than lung cancer

ment; patients who agreed are prescribed escitalopram (5-20 mg per day) by a psychiatrist. All other interventions in the collaborative care group are the same for patients who agreed and those who do not agree to take medication.

\section{EUC and non-distressed groups (comparison arms)}

The EUC and non-distressed groups receive an educational leaflet three times during the 12 -week treatment period. These patients also receive the typical clinical management for psychological difficulties, i.e., consultations with and/or visits to the psychiatric department based on their condition and agreement.

\section{Data collection and instruments at the follow-up assessments}

The schedule of assessment for the study is summarized in Table 3. All participants will be followed up at 12 and 32 weeks after enrollment. Additionally, the intervention group will be followed up at 2, 4, and 8 weeks after enrollment to collect detailed data regarding the intervention

\section{Assessment scales}

This study included the following assessment scales: Eastern Cooperative Oncology Group Performance Status; ${ }^{39}$ modified Medical Research Council (MMRC) dyspnea scale; ${ }^{40}$ Confusion Assessment Meth (CAM); ${ }^{41}$ Brief Psychiatric Rating Scale (BPRS)-suicidality subscale; ${ }^{42}$ Research Diagnostic Criteria for Insomnia/International Classification of Sleep Disorders-Second Edition (RDC/ICSD-2); ${ }^{43,44}$ Adult Lifestyles

Table 2. Session structure of intervention

\begin{tabular}{|c|c|c|}
\hline Session & Time & Content \\
\hline \multirow[t]{3}{*}{ Session 1} & 1st week & Introduction and relationship building \\
\hline & & Relaxation training: breathing exercises \\
\hline & & Education: nutrition and smoking cessation \\
\hline \multirow[t]{2}{*}{ Session 2} & 2nd week & Relaxation training: progressive muscle relaxation \\
\hline & & Mindful breathing \\
\hline \multirow[t]{2}{*}{ Session 3} & 3rd week & Experiencing and expressing emotions \\
\hline & & Relaxation training: guided imagery relaxation \\
\hline Session 4 & 4th week & $\begin{array}{l}\text { Cognitive work with anxiety and depression (e.g., Searching for alteration, weighing advantages and } \\
\text { disadvantages, Information seeking) }\end{array}$ \\
\hline \multirow[t]{2}{*}{ Session 5} & 6th week & Evaluating my support system \\
\hline & & Asking for support \\
\hline Session 6 & 8th week & Being active-I: activity scheduling \\
\hline \multirow[t]{2}{*}{ Session 7} & 10th week & Being active-II: activity scheduling \\
\hline & & Planning ahead \\
\hline \multirow[t]{2}{*}{ Session 8} & 12th week & Communication techniques \\
\hline & & Final review and wrap-up \\
\hline
\end{tabular}


Table 3. Schedule of assessment for the study

\begin{tabular}{|c|c|c|c|c|c|c|c|}
\hline & $\mathrm{B} 1$ & $2 \mathrm{~W}^{*}$ & $4 \mathrm{~W}^{*}$ & $8 \mathrm{~W}^{*}$ & $12 \mathrm{~W}$ & $32 \mathrm{~W}$ & 3 year \\
\hline Socio-demographic characteristics & $\mathrm{V}$ & & & & & & \\
\hline Clinical characteristics & $\mathrm{V}$ & & & & & & \\
\hline Records of anti-cancer treatment & $\mathrm{V}$ & $\mathrm{V}$ & $\mathrm{V}$ & $\mathrm{V}$ & $\mathrm{V}$ & $\mathrm{V}$ & \\
\hline Genetic/serologic information & $\mathrm{V}$ & & & & & & \\
\hline Disease status and survival & $\mathrm{V}$ & $\mathrm{V}$ & $\mathrm{V}$ & $\mathrm{V}$ & $\mathrm{V}$ & $\mathrm{V}$ & $\mathrm{V}$ \\
\hline \multicolumn{8}{|l|}{ Measurements } \\
\hline Big Five Inventory-10 & $\mathrm{V}$ & & & & & & \\
\hline Duke religion questionnaire & $\mathrm{V}$ & & & & & & \\
\hline ECOG-Performance Status & $\mathrm{V}$ & $\mathrm{V}$ & $\mathrm{V}$ & $\mathrm{V}$ & $\mathrm{V}$ & $\mathrm{V}$ & \\
\hline MMRC dyspnea scale & $\mathrm{V}$ & $\mathrm{V}$ & $\mathrm{V}$ & $\mathrm{V}$ & $\mathrm{V}$ & $\mathrm{V}$ & \\
\hline Confusion Assessment Method & $\mathrm{V}$ & $\mathrm{V}$ & $\mathrm{V}$ & $\mathrm{V}$ & $\mathrm{V}$ & $\mathrm{V}$ & \\
\hline BPRS-suicidality subscale & $\mathrm{V}$ & & & & $\mathrm{V}$ & $\mathrm{V}$ & \\
\hline RDC/ICSD-2 & $\mathrm{V}$ & & & & $\mathrm{V}$ & $\mathrm{V}$ & \\
\hline ALFI-MMSE & $\mathrm{V}$ & & & & $\mathrm{V}$ & $\mathrm{V}$ & \\
\hline MINI-MDD & $\mathrm{V}$ & & & & $\mathrm{V}$ & $\mathrm{V}$ & \\
\hline Montgomery Åsberg Depression Rating Scale & $\mathrm{V}$ & & $\mathrm{V}$ & & $\mathrm{V}$ & $\mathrm{V}$ & \\
\hline Hospital Anxiety and Depression Scale & $\mathrm{V}$ & $\mathrm{V}$ & $\mathrm{V}$ & $\mathrm{V}$ & $\mathrm{V}$ & $\mathrm{V}$ & \\
\hline Distress Thermometer & $\mathrm{V}$ & $\mathrm{V}$ & $\mathrm{V}$ & $\mathrm{V}$ & $\mathrm{V}$ & $\mathrm{V}$ & \\
\hline Screening questionnaire of restless leg syndrome & $\mathrm{V}$ & & & & $\mathrm{V}$ & $\mathrm{V}$ & \\
\hline Beck Hopelessness Scale & $\mathrm{V}$ & & & & $\mathrm{V}$ & $\mathrm{V}$ & \\
\hline EORTC QLQ c-30 & $\mathrm{V}$ & & & & $\mathrm{V}$ & $\mathrm{V}$ & \\
\hline Demoralization-II & & & & & & $\mathrm{V}$ & \\
\hline UKU side effect profile* & & $\mathrm{V}$ & $\mathrm{V}$ & $\mathrm{V}$ & $\mathrm{V}$ & & \\
\hline
\end{tabular}

*additional assessments for collaborative care group only. ALFI-MMSE: adult lifestyles and function interview of the mini-mental state exam, BPRS: brief psychiatric rating scale, ECOG: eastern cooperative oncology group, EORTC QLQ c-30: european organization for research and treatment of cancer core questionnaire, MINI-MDD: the mini international neuropsychiatric interview, MMRC: modified medical research council, RDC/ICSD-2: research diagnostic criteria for insomnia/international classification of sleep disorders-second edition, UKU: udvalg for kliniske undersogelser

and Function Interview of the Mini-Mental State Exam (ALFIMMSE) $;{ }^{45}$ DSM-IV criteria for major depressive disorder-the Mini International Neuropsychiatric Interview (MINI-MDD); ${ }^{46}$ Montgomery Åsberg Depression Rating Scale (MADRS); ${ }^{47}$ HADS; $;^{32,33} \mathrm{DT}^{34}$ the diagnostic criteria of the four screening questionnaires of the International Restless Leg Syndrome Study Group (IRLSSG); ${ }^{48}$ Beck Hopelessness Scale (BHS); ${ }^{49}$ European Organization for Research and Treatment of Cancer core questionnaire (EORTC QLQ c-30); ;0,51 and demoralization scale-II (DS-II). ${ }^{52}$ Disease status and survival data will be collected until 3 years after enrollment. Patients who enrolled in the intervention arm also completed the ECOG-PS, MMRC, CAM, HADS, and DT at 2, 4, and 8 weeks after enrollment and the MADRS at 4 weeks after enrollment. Patients who agreed to treatment with escitalopram are also assessed with the Udvalg for Kliniske Undersogelser (UKU) side-effects profile (UKU) side effect profile ${ }^{53}$ at 2, 4, 8, and 12 weeks after enrollment.

\section{Primary outcome measures}

The primary outcome measures are changes in the HADS-D and DT score at 12 and 32 weeks after enrollment.

\section{Secondary outcome measures}

Secondary outcome measures will include changes in the BPRS-suicidality subscale, RDC/ICSD-2, ALFI-MMSE, MINIMDD, MADRS, HADS-anxiety, BHS, EORTC QLQ c-30, DSII, disease status, and survival.

\section{Sample size estimation}

The necessary sample size was calculated using the G power tool $3.1^{54}$ with effect size specification as described by Cohen. ${ }^{55}$ Based on a design to produce $80 \%$ power to detect a medium effect size (0.25) using Cohen's $\mathrm{f}^{55}$ for a repeatedmeasures of analysis of variance (RMANOVA), the assumptions yielded a sample size of 159 patients. Because a previous study reported a $30 \%$ rate of cancer-related deaths in advanced 
lung cancer patients at 32 weeks, ${ }^{16}$ a dropout rate of $40 \%$ was predicted. Thus, a total of 267 patients (i.e., 89 subjects per group) will be enrolled in the study.

\section{Statistical analysis plan}

After all outcome data have been collected at 12 and 32 weeks after enrollment, a main analysis of the non-distressed, EUC, and collaborative care arms will be performed using RMANOVA. Additionally, a sub-analysis within the collaborative care arm comparing those who received collaborative care in combination with escitalopram versus those who did not receive escitalopram will be conducted using RMANOVA.

\section{Approval and registration}

The trial was approved by the Chonnam National University Hwasun Hospital Institutional Review Board (CNUHH 2014-056) and registered at https://cris.nih.go.kr (registration number: KCT0002127). The sub-analysis of antidepressant treatment in combination with collaborative care was also approved (CNUHH 2014-055) and registered (registration number: KCT0002128).

\section{Acknowledgments}

The research was funded by a grant of the Korea Health 21 R\&D, Ministry of Health and Welfare, Republic of Korea (HI10C2020) and National Research Foundation of Korea Grant (NRF-2015M3C7A1028899) to Professor JM Kim.

\section{Conflicts of Interest}

The authors have no potential conflicts of interest to disclose.

\section{Author Contributions}

Conceptualization: Jae-Min Kim, Seon-Young Kim, In-Jae Oh, YoungChul Kim. Formal analysis: Sung-Wan Kim, Seon-Young Kim. Funding acquisition: Jae-Min Kim. Investigation: Seon-Young Kim, Cheol-Kyu Park. Methodology: Jae-Min Kim, Il-Seon Shin. Supervision: Il-Seon Shin, Young-Chul Kim. Visualization: Seon-Young Kim. Writing-original draft: Jae-Min Kim, Seon-Young Kim. Writing_review \& editing: Jae-Min Kim, Seon-Young Kim, Sung-Wan Kim, Il-Seon Shin, Cheol-Kyu Park, InJae Oh, Young-Chul Kim

\section{ORCID iDs}

\section{Jae-Min Kim}

Seon-Young Kim

https://orcid.org/0000-0001-7409-6306

https://orcid.org/0000-0003-3185-9005

\section{REFERENCES}

1. Korea Central Cancer Registry. Annual report of cancer statistics in Korea in 2015. Goyang: National Cancer Center (South Korea); Available at: http://ncc.re.kr/cancerStatsView.ncc?bbsnum=418\&searchKey=tot al\&searchValue=\&pageNum=1. Accessed December 28, 2018.

2. Moghaddam N, Coxon H, Nabarro S, Hardy B, Cox K. Unmet care needs in people living with advanced cancer: a systematic review. Support Care Cancer 2016;24:3609-3622.

3. Heo J, Chun M, YT Oh, Noh OK, Kim L. Psychiatric comorbidities among breast cancer survivors in South Korea: a nationwide population-based study. Breast Cancer Res Treat 2017;162:151-158.

4. National Comprehensive Cancer Network. NCCN practice guidelines in Oncology, Distress management, version 2. 2018. Available at: https:// www.ncen.org/store/login/login.aspx?ReturnURL=https://www.nccn. org/professionals/physician_gls/pdf/distress.pdf. Accessed December 28, 2018.

5. Björkhem-Bergman L, Bergman P. Vitamin D and patients with palliative cancer. BMJ Support Palliat Care 2016;6:287-291.

6. Chang WP, Lin CC. Relationships of salivary cortisol and melatonin rhythms to sleep quality, emotion, and fatigue levels in patients with newly diagnosed lung cancer. Eur J Oncol Nurs 2017;29:79-84.

7. Kim JM, Kim SW, Stewart R, Kim SY, Shin IS, Park MH, et al. Serotonergic and BDNF genes associated with depression 1 week and 1 year after mastectomy for breast cancer. Psychosom Med 2012;74:8-15.

8. Sanders SL, Bantum EO, Owen JE, Thornton AA, Stanton AL. Supportive care needs in patients with lung cancer. Psychooncology 2010;19:480489.

9. Cohen A, Ianovski LE, Frenkiel S, Hier M, Zeitouni A, Kost K, et al. Barriers to psychosocial oncology service utilization in patients newly diagnosed with head and neck cancer. Psychooncology 2018;27:2786-2793.

10. Mosher CE, Winger JG, Hanna N, Jalal SI, Fakiris AJ, Einhorn LH, et al. Barriers to mental health service use and preferences for addressing emotional concerns among lung cancer patients. Psychooncology 2014;23: 812-819.

11. Sighinolfi C, Nespeca C, Menchetti M, Levantesi P, Belvederi Murri M, et al. Collaborative care for depression in European countries: a systematic review and meta-analysis. J Psychosom Res 2014;77:247-263.

12. Ell K, Xie B, Quon B, Quinn DI, Dwight-Johnson M, Lee PJ. Randomized controlled trial of collaborative care management of depression among low-income patients with cancer. J Clin Oncol 2008;26:4488-4496.

13. Kroenke K, Theobald D, Wu J, Norton K, Morrison G, Carpenter J, et al. Effect of telecare management on pain and depression in patients with cancer: a randomized trial. JAMA 2010;304:163-171.

14. Strong V, Waters R, Hibberd C, Murray G, Wall L, Walker J, et al. Management of depression for people with cancer (SMaRT oncology 1): a randomised trial. Lancet 2008;372:40-48.

15. Sharpe M, Walker J, Holm Hansen C, Martin P, Symeonides S, Gourley $\mathrm{C}$, et al. Integrated collaborative care for comorbid major depression in patients with cancer (SMaRT Oncology-2): a multicentre randomised controlled effectiveness trial. Lancet 2014;384:1099-1108.

16. Walker J, Hansen CH, Martin P, Symeonides S, Gourley C, Wall L, et al. Integrated collaborative care for major depression comorbid with a poor prognosis cancer (SMaRT Oncology-3): a multicentre randomised controlled trial in patients with lung cancer. Lancet Oncol 2014;15:1168-1176.

17. Li M, Kennedy EB, Byrne N, Gérin-Lajoie C, Katz MR, Keshavarz H, et al. Systematic review and meta-analysis of collaborative care interventions for depression in patients with cancer. Psychooncology 2017;26: 573-587.

18. Goldstraw P, Chansky K, Crowley J, Rami-Porta R, Asamura H, Eberhardt WE, et al. The IASLC Lung Cancer Staging Project: Proposals for Revision of the TNM Stage Groupings in the Forthcoming (Eighth) Edition of the TNM Classification for Lung Cancer. J Thorac Oncol 2016;11: 39-51.

19. Zabora J, BrintzenhofeSzoc K, Curbow B, Hooker C, Piantadosi S. The prevalence of psychological distress by cancer site. Psychooncology 2001;10:19-28.

20. Fang F, Fall K, Mittleman MA, Sparén P, Ye W, Adami HO, et al. Suicide and cardiovascular death after a cancer diagnosis. N Engl J Med 2012; 366:1310-1318.

21. Hopwood P, Stephens RJ. Depression in patients with lung cancer: prevalence and risk factors derived from quality-of- life data. J Clin Oncol 2000;18:893-903.

22. Akechi T, Okamura H, Nishiwaki Y, Uchitomi Y. Psychiatric disorders and associated and predictive factors in patients with unresectable nonsmall cell lung carcinoma: a longitudinal study. Cancer 2001;92:26092622.

23. Gilbody S, Bower P, Fletcher J, Richards D, Sutton AJ. Collaborative care 
for depression: a cumulative meta-analysis and review of longer-term outcomes. Arch Intern Med 2006;166:2314-2321.

24. Kim SY, Kim JM, Kim SW, Shin IS, Yoon JS, Shim HJ. Management of depression in terminally Ill cancer patients. Korean J Psychopharmacol 2010;21:51-61.

25. Akechi T, Uchida M, Nakaguchi T, Okuyama T, Sakamoto N, Toyama $\mathrm{T}$, et al. Difference of patient's perceived need in breast cancer patients after diagnosis. Jpn J Clin Oncol 2015;45:75-80.

26. Flöck A, Zobel A, Bauriedel G, Tuleta I, Hammerstingl C, Höfels S, et al. Antiplatelet effects of antidepressant treatment: a randomized comparison between escitalopram and nortriptyline. Thromb Res 2010;126:e83e87.

27. Funk KA, Bostwick JR. A comparison of the risk of QT prolongation among SSRIs. Ann Pharmacother 2013;47:1330-1341.

28. Rammstedt B, John OP. Measuring personality in one minute or less: a 10-item short version of the Big Five Inventory in English and German. J Res Pers 2007;41:203-212.

29. Kim SY, Kim JM, Yoo JA, Bae KY, Kim SW, Yang SW, et al. Standardization and validation of the Big Five Inventory-Korean Version (BFI-K) in elders. Korean J Biol Psychiatry 2010;17:15-25.

30. Koenig H, Parkerson Jr GR, Meador KG. Religion index for psychiatric research. Am J Psychiatry 1997;154:885-886.

31. Jang JE, Kim SW, Kim SY, Kim JM, Park MH, Yoon JH, et al. Religiosity, depression, and quality of life in Korean patients with breast cancer: a 1-year prospective longitudinal study. Psychooncology 2013;22:922929.

32. Zigmond AS, Snaith RP. The hospital anxiety and depression scale. Acta Psychiatr Scand 1983;67:361-370.

33. Oh SM, Min KJ, Park DB. A study on the standardization of the Hospital Anxiety and Depression Scale for Koreans: a comparison of normal, depressed and anxious groups. J Korean Neuropsychiatr Assoc 1999;38:289-296.

34. Roth AJ, Kornblith AB, Batel-Copel L, Peabody E, Scher HI, Holland JC. Rapid screening for psychologic distress in men with prostate carcinoma. Cancer 1998;82:1904-1908.

35. Shim EJ, Shin YW, Jeon HJ, Hahm BJ. Distress and its correlates in Korean cancer patients: pilot use of the distress thermometer and the problem list. Psychooncology 2008;17:548-555.

36. Walker J, Sharpe M. Depression care for people with cancer: a collaborative care intervention. Gen Hosp Psychiatry 2009;31:436-441.

37. Moorey S, Greer S. Oxford Guide to CBT for People with Cancer. 2nd Edition. New York: Oxford University Press; 2012.

38. Satterfield JM. Minding the Body. Seoul: SIGMA press; 2014 (Lee JH, Translator. Original Work Published by Oxford University Press; 2008).

39. Oken MM, Creech RH, Tormey DC, Horton J, Davis TE, McFadden ET, et al. Toxicity and response criteria of the Eastern Cooperative Oncology Group. Am J Clin Oncol 1982;5:649-655.

40. Mahler D, Wells C. Evaluation of clinical methods for rating dyspnea.
Chest 1988;93:580-586

41. Inouye SK, Dyck CH, Alessi CA, Balkin S, Siegal AP, Horwitz RI. Clarifying confusion: the confusion assessment method. A new method for detection of delirium. Ann Int Med 1990;113:941-948.

42. Overall JE, Gorham DR. The brief psychiatric rating scale. Psychol Rep 1962;10:799-812.

43. Edinger JD, Bonnet MH, Bootzin RR, Doghramji K, Dorsey CM, Espie $\mathrm{CA}$, et al. Derivation of research diagnostic criteria for insomnia: report of an American Academy of Sleep Medicine Work Group. Sleep 2004; 27:1567-1596.

44. American Academy of Sleep Medicine. International Classification of Sleep Disorders: Diagnostic and Coding Manual, 2nd Ed, (ICSD-2). Rochester, MN: Sleep Disorders Association; 2005.

45. Roccaforte WH, Burke WJ, Bayer BL, Wengel SP. Validation of a telephone version of the mini-mental state examination. J Am Geriatr Soc 1992;40:697-702.

46. Sheehan DV, Lecrubier Y, Sheehan KH, Amorim P, Janavs J, Weiller E, et al. The Mini-International Neuropsychiatric Interview (M.I.N.I.): the development and validation of a structured diagnostic psychiatric interview for DSM-VI and ICD-10. J Clin Psychiatry 1988;59:22-33.

47. Montgomery SA, Asberg M. A new depression scale designed to be sensitive to change. Br J Psychiatry 1979;134:382-389.

48. Allen RP, Picchietti D, Hening WA, Trenkwalder C, Walters AS, Montplaisi J, et al. Restless legs syndrome: diagnostic criteria, special considerations, and epidemiology. A report from the restless legs syndrome diagnosis and epidemiology workshop at the National Institutes of Health. Sleep Med 2003;4:101-119.

49. Beck AT, Weissman A, Lester D, Trexler L. The measurement of pessimism: the hopelessness scale. J Consult Clin Psychol 1974;42:861-865.

50. Aaronson NK, Ahmedzai S, Bergman B, Bullinger M, Cull A, Duez NJ, et al. The European Organization for Research and Treatment of Cancer EORTC QLQ-C30: A quality-of-life instrument for use in international clinical trials in oncology. J Natl Cancer Inst 1993;85:365-376.

51. Yun YH, Park YS, Lee ES, Bang SM, Heo DS, Park SY, et al. Validation of the Korean version of the EORTC QLQ-C30. Qual Life Res 2004;13: 863-868.

52. Robinson S, Kissane DW, Brooker J, Michael N, Fischer J, Franco M, et al. Refinement and revalidation of the demoralization scale: the DS-IIinternal validity. Cancer 2016;122:2251-2259.

53. Lingjaerde O, Ahlfors UG, Bech P, Dencker SJ, Elgen K. The UKU side effect rating scale. A new comprehensive rating scale for psychotropic drugs and a cross-sectional study of side effects in neuroleptictreated patients. Acta Psychiatr Scand Suppl 1987;334:1-100.

54. Faul F, Erdfelder E, Buchner A, Lang AG. Statistical power analyses using $\mathrm{G}^{*}$ Power 3.1: tests for correlation and regression analyses. Behav Res Methods 2009;41:1149-1160.

55. Cohen J. Statistical Power Analysis for the Behavioral Sciences, 2nd Edition. NJ: Routledge; 1988. 